\title{
Calibration Curves of Culture Density Assessed by Spectrophotometer for Three Microalgae (Nephroselmis sp., Amphidinium carterae and Phormidium sp.)
}

\author{
George N. Hotos, Despoina Avramidou, and Vlassoula Bekiari
}

\section{ABSTRACT}

This study concerns the finding of an effective operational equation relating the measured absorpbance (or O.D. - optical density) in a spectrophotometer of the suspended cells of microalgae to their cell density (c.d.) in culture in order to construct calibration curves for use in culture operations. The microalgae examined were the chlorophyte Nephroselmis sp., the dinophyte Amphidinium carterae and the filamentous cyanobacterium Phormidium sp. Wavelengths of 430 and $680 \mathrm{~nm}$ were selected that correspond to chlorophyll-a peaks of their absorption spectra were used and additionally 750 and $570 \mathrm{~nm}$ where absorbance was not peaked. From all equations extracted best fitness with strong predictive values were those of a logarithmic type: $0 . D .=0,9328 * \ln ($ c.d. $)-14,108$ $\left(\mathbf{R}^{2}=0,9943\right)$ at $680 \mathrm{~nm}$ for Nephroselmis, a power equation: O.D. $=0,0000009 *(\text { c.d. })^{0,9195}\left(R^{2}=0,9936\right)$ at $680 \mathrm{~nm}$ for Amphidinium and a polynomial second order: $\quad$ O.D. $=0,9869(\text { c.d. })^{2}+2,4393($ c.d. $)+0,2666$ $\left(R^{2}=0,9737\right)$ at $570 \mathrm{~nm}$ for Phormidium.

Keywords: Absorbance, cell density, spectrophotometry, calibration curve, microalgae, Nephroselmis, Amphidinium, Phormidium.
Published Online: December 10, 2020

ISSN: $2684-5199$

DOI :10.24018/ejbio.2020.1.6.132

\section{George N. Hotos *}

Department of Animal Production, Fisheries and Aquaculture, University of Patras, Greece.

(e-mail: ghotos@upatras.gr)

Despoina Avramidou

Department of Animal Production,

Fisheries and Aquaculture, University of Patras, Greece.

Vlassoula Bekiari

Department of Animal Production, Fisheries and Aquaculture, University of Patras, Greece.

*Corresponding Author

\section{INTRODUCTION}

With the modern world facing increasing carbon dioxide levels in the atmosphere already reaching $450 \mathrm{ppm}$ [1] that could contribute to global warming as stated by the IPCC, a remedy can only ensue from trapping as much $\mathrm{CO}_{2}$ as possible by natural means. Photosynthesis is the answer to this issue and algae can be the key element to this procedure. Microalgae especially possess a central role in $\mathrm{CO}_{2}$ sequestration globally as they are 10-50 times more efficient in trapping it from the atmosphere as compared to terrestrial plants [2]. Additionally, microalgae are mass cultured for biofuels, feedstock and value added products, wastewater treatment and nutrient removal to mention their main uses [3]. The list of the cultured microalgae for various uses is continuously enlarging and knowledge accumulates concerning their particular needs for efficient production. Culture techniques for various species are adapted to their particular requirements concerning environmental conditions (light, salinity, temperature), chemicals (nutrients, $\mathrm{pH}$, toxic substances) and special conformation of culture support (e.g. aeration, $\mathrm{CO}_{2}$ addition, vessel configuration). The aim is to produce maximum algal biomass using in the most economical way the necessary labor, energy, space, and time. Common practice to any type of microalgal culture is the continuous monitoring of the cultured algal density in terms of cells/ml or dry weight
(g/L) to mention but the most common of them. To accomplish that, frequent sampling of the cultured biomass is a prerequisite and a small amount of liquid is examined microscopically for counting the cells, or an amount of liquid is filtrated and then dried for hours in an oven and then weighted in order to calculate the dry weight. Both are time consuming procedures especially when a lot of culture vessels are employed. Monitoring of culture density can be greatly simplified by just recording optical density (absorbance) of culture samples and deducing the algal density using a reference regression line of optical density (O.D.) to cell density. This is accomplished by measuring one time several samples with different densities and counting with a haematocytometer the number of cells per $\mathrm{ml}$. Then each cell density is assigned to the relevant O.D. in a spectrophotometer at an appropriate wave length. Afterwards only O.D. need to be measured and the cell density is calculated by the regression equation. There are in the literature [4]-[9] various regression equations of this type for several microalgae species. However, there are also many microalgae with culture potential for which this relation has never been attempted. This is exactly where our work aims, that is to present reference regression equations of O.D.'s to cell densities for selected microalgae that are promising for producing value products after being mass cultured in a feasible way.

Among the microalgae the dinoflagellates are a source of 
several bioactive substances [10], [11]. Amphidinols and karlotoxins are produced from Amphidinium carterae using simple culture processes [12]-[14] the only constrain being its sensitivity to hydrodynamic stress [15]. Additionally, bioactive production oriented mass culture of Amphidinium (being a dinoflagellate) can yield other high-value chemicals such as carotenoids (e.g. peridinin) and fatty acids (EPA and DHA) that are used in numerous nutraceutical and pharmaceutical applications [16], [17]. So, the mass culture of $A$. carterae that have been successfully attempted using LED-illuminated photobioreactor [13], [14] will much benefit from a guide reference relation of O.D.-cells per $\mathrm{ml}$.

Data on culture of the chlorophyte Nephroselmis sp. are scarce. Its mass production has been successful [18], [19] and it has been recorded as an efficient producer of lipids and C16-C18 FAME in the order of $39,4 \%$ and $77,8 \%$ respectively in yields from 0,4116 to $0,5468 \mathrm{~g} / \mathrm{L}$ dry cell weight. So, for this species also a relation of optical density to cells per ml would serve as a useful tool in its culture.

Phormidium sp. is a filamentous non heterocytous cyanobacterium that has potential of producing several useful compounds like antioxidant carotenoids and phycobilins and novel bioactive toxins for pharmaceutical applications [20]-[22]. Its initial cultures in our laboratory exhibited a high growth rate in various salinities and an impressive sedimentation rate that could serve in its afterculture concentration. So, it was selected as a promising alga for our experimentation.

Motivated by the fact that although monitoring and control of algal mass growth are an essential tool in the microalgae culture its detailed investigation has not drawn the attention it deserves [23], we attempt here to offer useful regression models for predicting algal growth of selected species by means of spectrophotometrically measured optical density (O.D.) at certain wave lengths.

\section{MATERIALS AND MethodS}

The microalgae species used (Fig. 1) were of two kinds, single-celled (Amphidinium carterae and Nephroselmis sp.) and filamentous (Phormidium sp.). All are marine species collected from the lagoons of W. Greece and Phormidium especially from the evaporation pond of Messolonghi salterns (salinity $70 \mathrm{ppt}$ ). They were isolated from raw samples by means of serial dilutions and kept in pure nonaxenic cultures in Erlenmeyer vials of $500 \mathrm{ml}$ at the appropriate salinity in which previously exhibited best growth (40 ppt for Amphidinium and Phormidium, $60 \mathrm{ppt}$ for Nephroselmis). The microalgae were cultivated in the salinities mentioned in triplicate 1 L Erlenmeyer glass flasks using sterilized and salinity adjusted seawater fertilized with all minerals contained in a Walne formula. Temperature was kept at $20 \pm 1{ }^{\circ} \mathrm{C}$ and illumination was provided by 20 watt $1600 \mathrm{~lm}$ LED lamps with an intensity of 7500-8000 lux at the surface of the culture vessels (measured by a Bioblock LX-101 lux meter) generating an active radiation of 150-160 $\mu \mathrm{mol}$ photons $\mathrm{m}^{-2} \mathrm{~s}^{-1}$. Continuous aeration was supplied to the vessels via $1 \mathrm{ml}$ glass pipettes that created small bubbles of filtered air through $0,45 \mu \mathrm{m}$ cut-off cartridge fed by a 2.5 $\mathrm{hp}$ blower with an average flow of $60 \mathrm{~cm}^{3} \mathrm{~s}^{-1}$.
Spectrophotometric measurements were performed using a Shimadzu UVmini-1240 UV-visible spectrophotometer. For each of the 3 species analyzed the absorption spectrum in the range of $400-800 \mathrm{~nm}$ was first inspected to find the absorption peaks in order to serve as a guide for the wave length to be selected in the regression model of O.D.-cell density.

Cultures were started with inoculum of $100 \mathrm{ml}$ taken from a mature culture of each species and filling the experimental vessels with $900 \mathrm{ml}$ sterilized and fertilized seawater of the appropriate salinity. Every day aliquots of each vessel fixed with Lugol solution were measured for cellular density in a Neubauer haemocytometer using Leica DM-1000 microscope at 40X magnification. The O.D. of an untreated aliquot was measured in the spectrophotometer at the wave lengths selected. Care was taken before measurements for the aliquots to be properly agitated to avoid sedimentation of cells (most prominent in Phormidium) that could distort their actual density calculation.

APHA method (APHA, 2012) indicates 750, 664, 647 and $630 \mathrm{~nm}$ as the wavelengths most appropriate for measuring O.D. in microalgae cell density calculations. From these we selected $750 \mathrm{~nm}$ for all species as it is a wave length well beyond the absorbance peak of the chlorophylls in all species examined. For Phormidium we selected also 430 and $680 \mathrm{~nm}$ (chlorophyll-a peaks) and additionally 570 $\mathrm{nm}$ based on the fact that this is a wave length compromising the absorbance of the sum of its accessory pigments (carotenoids and phycobilins) present in cyanobacteria. For Nephroselmis and Amphidinium 430 and $680 \mathrm{~nm}$ that coincide with the lower and higher chlorophylla peaks were also selected. Measurements were done on a daily basis following the population growth of the cultures. At the peak of the growth phase of each species $\left(\sim 60 \times 10^{6}\right.$ cells $/ \mathrm{ml}$ for Nephroselmis, $\sim 5$ × $10^{6}$ cells $/ \mathrm{ml}$ for Amphidinium and $\sim 1,2$ g D.W./L for Phormidium) aliquots were taken and their cell density was measured. Subsequently by serial dilutions in $10 \%$ steps of the initial aliquot of each species 9 different concentrations were made and their O.D. was recorded in order to construct the calibration reference curve of O.D. - cell density. However, in the case of Phormidium cell density was measured in terms of cells dry weight per liter as counting its long filaments in haematocytometer was impossible. To accomplish measurement a quantity of $100 \mathrm{ml}$ of culture was filtered in a Heto-SUE-3Q vacuum generator with Whatman paper (pores $\sim 11 \mu \mathrm{m}$, Edevor $\mathrm{Nr} 20,9 \mathrm{~cm}$ ), washed with distilled water to remove salt and then by drying the filter in an oven ( 3 hours at $110^{\circ} \mathrm{C}$ ) its dry weight was recorded to the 3rd decimal in a KERN-EG 620-3NM electronic balance. This procedure was performed 3 times during the 10 days period that culture lasted and O.D. measurements were also taken. Additionally, O.D. was also measured daily. At day 10 the experiment terminated, a quantity of Phormidium was filtrated and its dry weight calculated while its O.D. was also measured. From the same vessel serial dilutions of $10 \%$ steps were prepared and their O.D.'s recorded. The dry weights allocated to these O.D.'s were simply calculated and so a calibration curve was constructed. Finally, the calibration curve presented here for Phormidium was based on the pooled data of O.D.-dry 
weight relation from any kind of measurements taken in the experiment. Similarly, pooled data were also used for the other two algae as well. All data were analyzed with Excel software to extract the functions relating O.D. to cell density. Of all possible equations relating O.D. to cell density for a particular wavelength it was selected that with the greatest Pearson correlation coefficient $\left(\mathrm{R}^{2}\right)$.

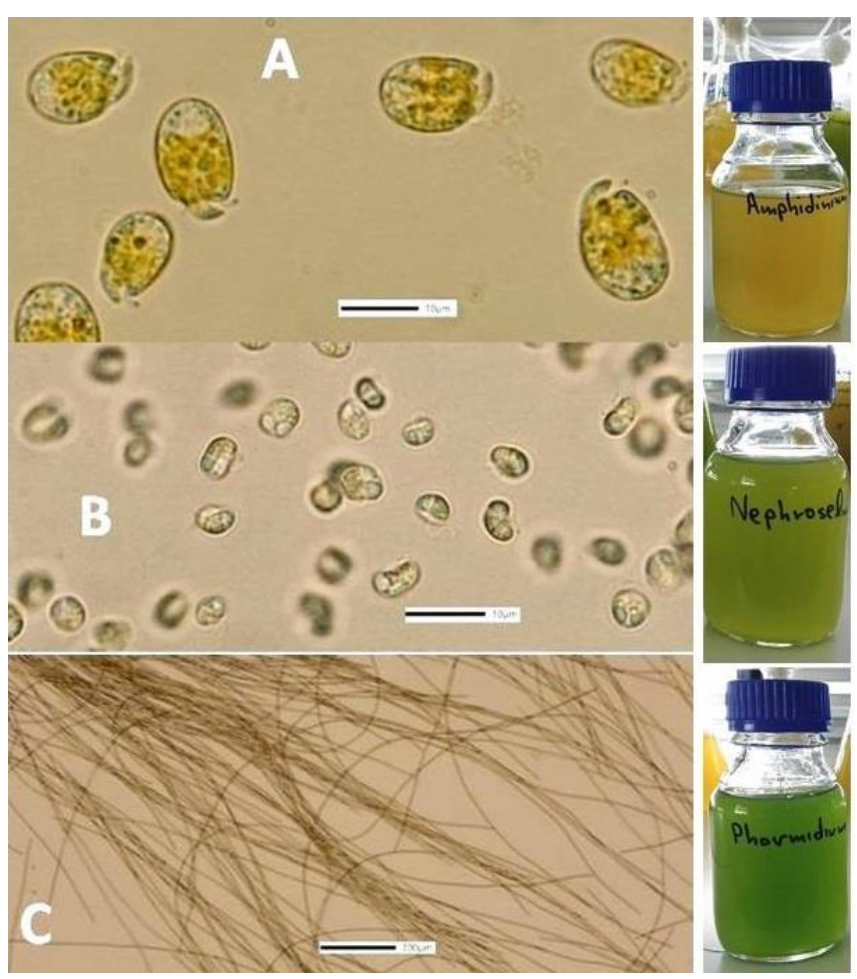

Fig. 1. Photonic microscope images of the microalgae cells of this study with a sample of their culture aside in order to show their color in their exponential phase of growth. A: Amphidinium carterae, B: Nephroselmis sp., C: Phormidium sp.

In order to validate the efficiency of the constructed equations for each species, the percentile deviation for the measured and predicted O.D.'s was calculated using the equation [24]:

$$
\text { Percentile deviation }=\left(\frac{O \cdot D \cdot o b s .-O \cdot D \cdot \text { pred } .}{O \cdot D \cdot o b s .}\right) \times 100
$$

Following that, the data were analyzed and the wavelength at which the pooled percentiles presented the least Standard Error and Standard Deviation was suggested for use judged to be of the highest accuracy among the others.

\section{RESULTS AND DISCUSSION}

The absorbance spectra of the microalgae examined are shown in Fig. 2, 3 and 4, PAR range (400-700) of wavelengths is included in them. The spectra were measured at different growth stages of the algae (that is: induction, exponential and stationary phases) and showed almost identical pattern so the selected spectrum of each species presented here is that corresponding to the end of the exponential phase. All three species exhibited two prominent peaks at the regions of $\sim 430$ and $\sim 680 \mathrm{~nm}$ corresponding to the absorbance maxima of chlorophyll-a.
Slight differences of the maximum absorbance for the microalgae tested and for other species found in the literature can be attributed to differences in the particular contents of chlorophylls ( $\mathrm{a} \& \mathrm{~b}$ for chlorophytes, a \& c for dinoflagellates and cyanobacteria) and carotenoids or billiproteins present in the cells [25], [26]. For the convenience of similarity in the presentation of a useful wavelength for all the tested algae we smoothened out the small peak differences among them and choose 430 and 680 $\mathrm{nm}$ as the working wavelengths for all 3 algae. Presumably at the above two wavelengths (430 and $680 \mathrm{~nm})$ representing the wavelengths of maximum sensitivity to quantity for the microalgae examined, the relationship between absorbance and cell density should be of the highest accuracy. Such a conclusion would be meaningless without, for the sake of comparison, testing additional wavelengths at which absorbance is minimum. So the chosen wavelengths of $750 \mathrm{~nm}$ for all species and additionally $570 \mathrm{~nm}$ for Phormidium were tested to see if they can also be useful to predict cell density on the ground that at these wavelengths absorbance will express nothing but turbidity alone.

The wavelengths tested resulted in very high overall Pearson correlation coefficients $\left(\mathrm{R}^{2}>0,97\right)$ for all algae indicating that the functions chosen were strong meaning that measured cell density shows high positive correlation with absorbance explaining more than $90 \%$ of the variance [24]. Instead of a simple linear relation of O.D. to cell density a power or polynomial or logarithmic function were chosen depending on the highest $\mathrm{R}^{2}$ resulted. With power equations it was evident that $\mathrm{b}$ coefficients were different from unity an indication that absorbance does not increase linearly with cell density. If $\mathrm{b}$ was unity, then a linear model would be justified. In Nephroselmis and Amphidinium where power equations were selected on the basis of best fitness, $b$ values were lower from unity indicating that absorbance decreases with cell density due presumably to some kind of a cell to cell shading effect. In the case of Phormidium the situation was different as the best fitness in all wavelengths tested resulted from application of a polynomial equation of 2 nd order with $\mathrm{R}^{2}$ values close to 0,98 .

For Nephroselmis (Fig. 2) measurements at $430 \mathrm{~nm}$ gave the highest regression coefficient $\left(\mathrm{R}^{2}=0,9903\right)$ using the power equation: O.D.430 $=0,000005 \mathrm{x}$ (cell dens. $)^{0,7467}$ with the $b$ value $(0,7467)$ indicative of a decreasing rate of absorbance (O.D.) with cell density. On the contrary at 680 and $750 \mathrm{~nm}$ the higher $\mathrm{R}^{2}(0,9943$ and 0,994 respectively) ensued from the logarithmic equations: O.D.680 $=0,9328 \mathrm{x}$ $\ln$ (cell dens.)-14,108 and O.D. $750=0,6829 \times \ln$ (cell dens.)10,115 respectively.

For Amphidinium (Fig. 3) at the wavelengths of 430 and $680 \mathrm{~nm}$ power equations resulted in best fits with $\mathrm{R}^{2}$ very high all above 0,99 . At the wavelength of $750 \mathrm{~nm}$ a linear regression exhibited the best fitness. The equations are: O.D.430 $=0,0000009 \times$ (cell dens. $)^{0,9199}$, O.D.680 $=0,0000009$ $\mathrm{x}$ (cell dens. $)^{0,9195}$ and O.D. $750=0,0000002 \mathrm{x}$ (cell dens. $)+$ 0,0673 . The power equations have $b$ values close to unity meaning that absorbance (O.D.) is not decreasing substantially with cell density.

For Phormidium (Fig. 4) being a filamentous cyanobacterium whose cell density calculation is somewhat 
cumbersome due to the multistep method of calculation (filtration paper weight, filtration of culture, drying of the concentrate, final weighing) with inherent intrusion of bias errors, the plotted values of O.D. to cell density presented greater variation than the other 2 algae. Nevertheless the relating equations were satisfactory with the best fit for the polynomial ones: O.D.430 $=0,9893$ (c.d. $)^{2}+3,132$ (c.d.) $+0,3298$ $\left(\mathrm{R}^{2}=0,9855\right), \quad$ O.D. $680=1,051$ (c.d. $)^{2}+2,874$ (c.d. $)+0,292$ $\left(\mathrm{R}^{2}=0,9841\right), \quad$ O.D. $750=0,8945$ (c.d. $)^{2}+2,2587$ (c.d. $)+0,2233$ $\left(\mathrm{R}^{2}=0,9748\right)$ and O.D. $570=0,9869$ (c.d. $)^{2}+2,4392$ (c.d. $)+0,2666$ $\left(\mathrm{R}^{2}=0,9737\right)$.

Rather limited studies monitored algal culture growth using spectrophotometry [9], [27]. [28] and in all of them wavelengths of around $680 \mathrm{~nm}$ was a key value for measurements. Obviously $680 \mathrm{~nm}$ is a compromise value of the slight variations of absorbance peaks in the range of 675-686 that different algae exhibit due to their absorbance maxima of their chlorophyll-a. In all studies $680 \mathrm{~nm}$ proved a good predictive wavelength for biomass monitoring. This was also the case of the present study as for all 3 algae examined its predictive use is strong. This is of a particular importance as the 3 algae belong to different taxa (chlorophyta, dinophyta, cyanobacteria) and probably it is a clue that $680 \mathrm{~nm}$ can be a universal tool for use in any taxonomic group of microalgae culture. Strangely enough the other chlorophyll-a peak of $430 \mathrm{~nm}$ has not been used in relevant studies. In the present study $430 \mathrm{~nm}$ proved to be equally effective to $680 \mathrm{~nm}$ in constructing the calibration curves in all 3 algae. So on the ground of selecting wavelengths based on absorption spectra and in particular those of the chlorophyll-a maxima, irrespectively of the slight differences of maximum absorbance among species in the areas of $\sim 430$ and $\sim 680 \mathrm{~nm}$, selecting anyone of them (430 or 680) will be correct.
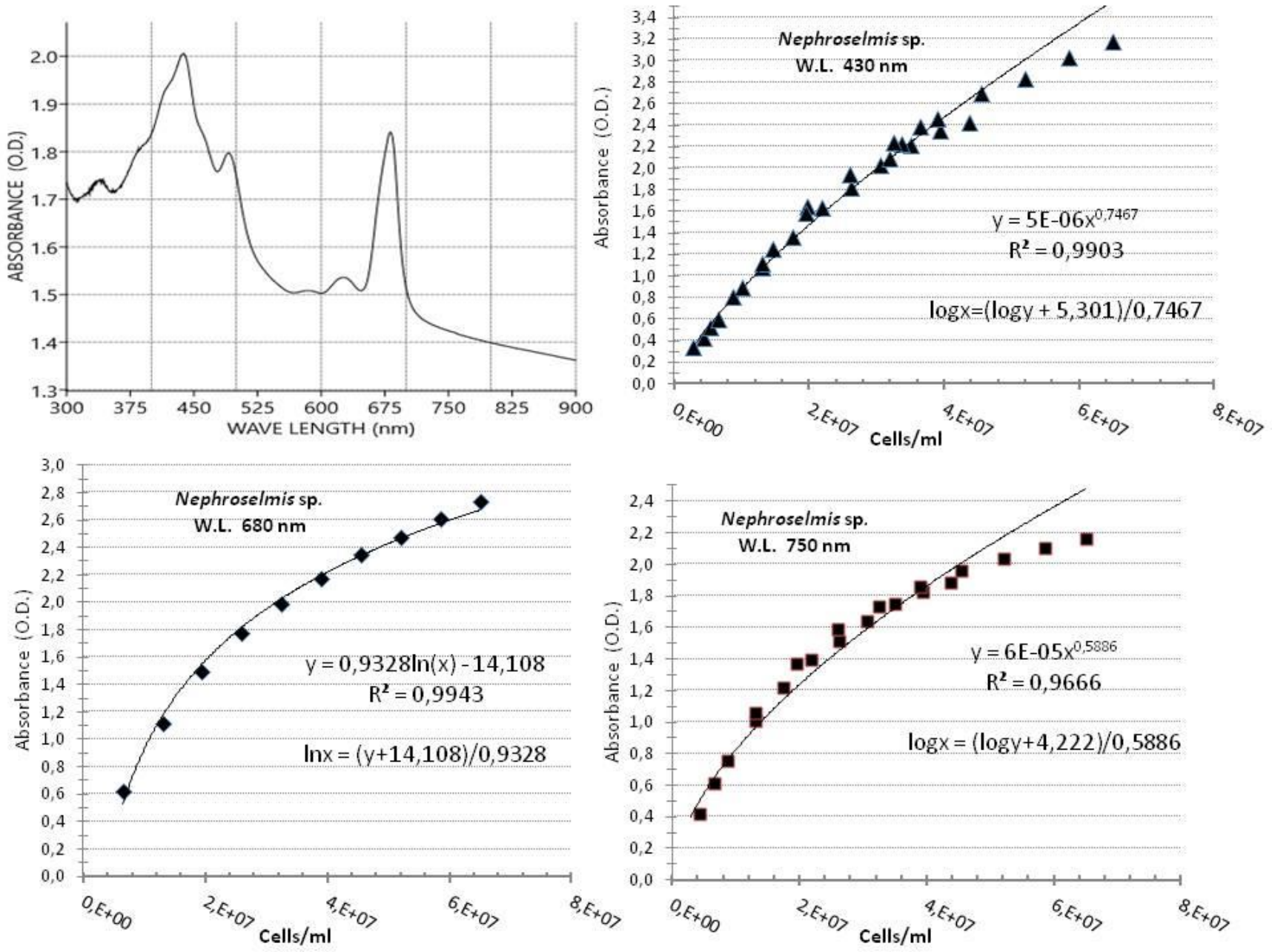

Fig. 2. The absorbance spectrum (upper left) and the relationship between absorbance and cell density for Nephroselmis sp. at three wavelengths (430, $680 \& 750 \mathrm{~nm})$ 
European Journal of Biology and Biotechnology www.ejbio.org
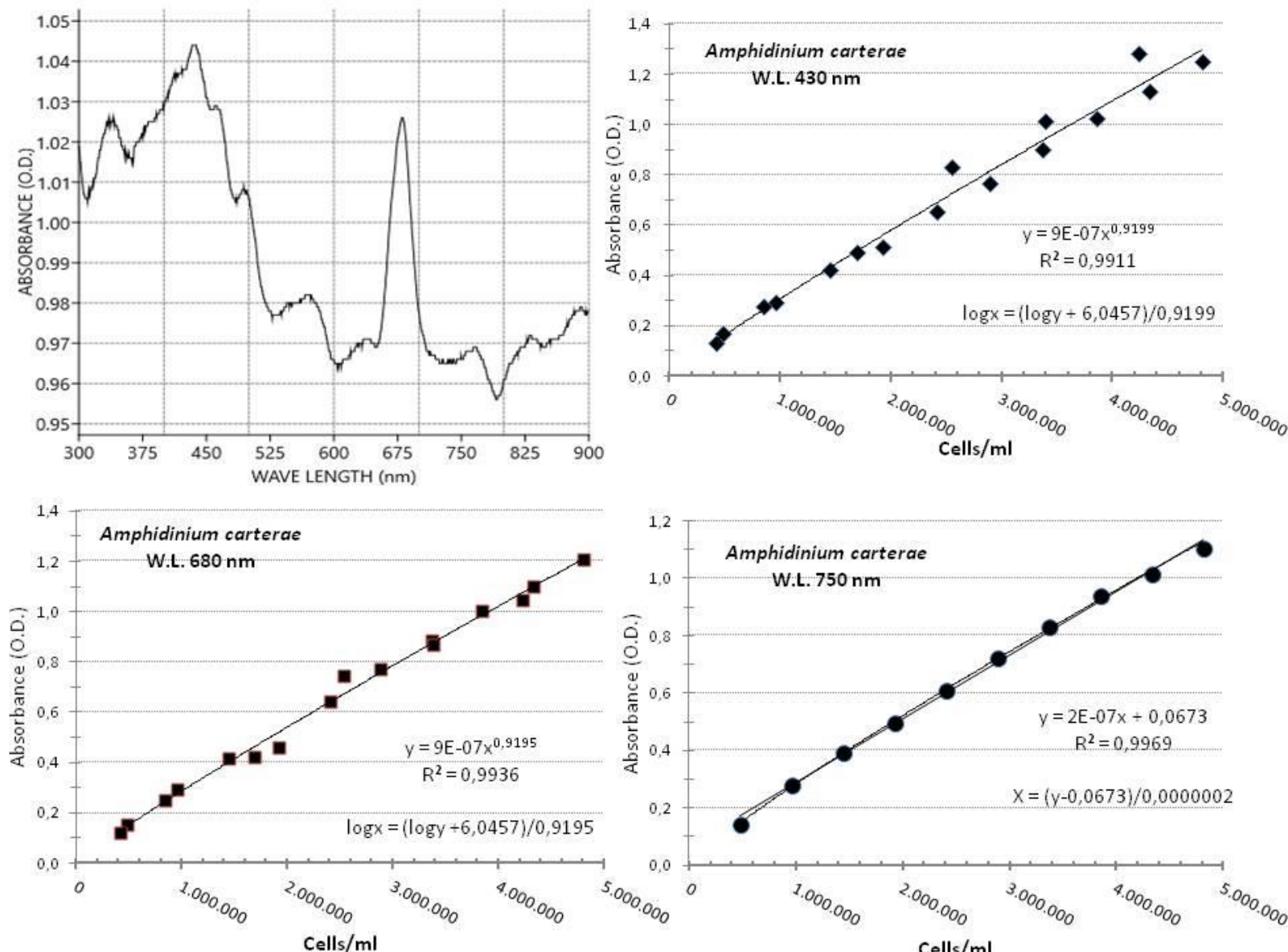

Fig. 3. The absorbance spectrum (upper left) and the relationship between absorbance and cell density for Amphidinium carterae at three wavelengths (430, $680 \& 750 \mathrm{~nm})$.
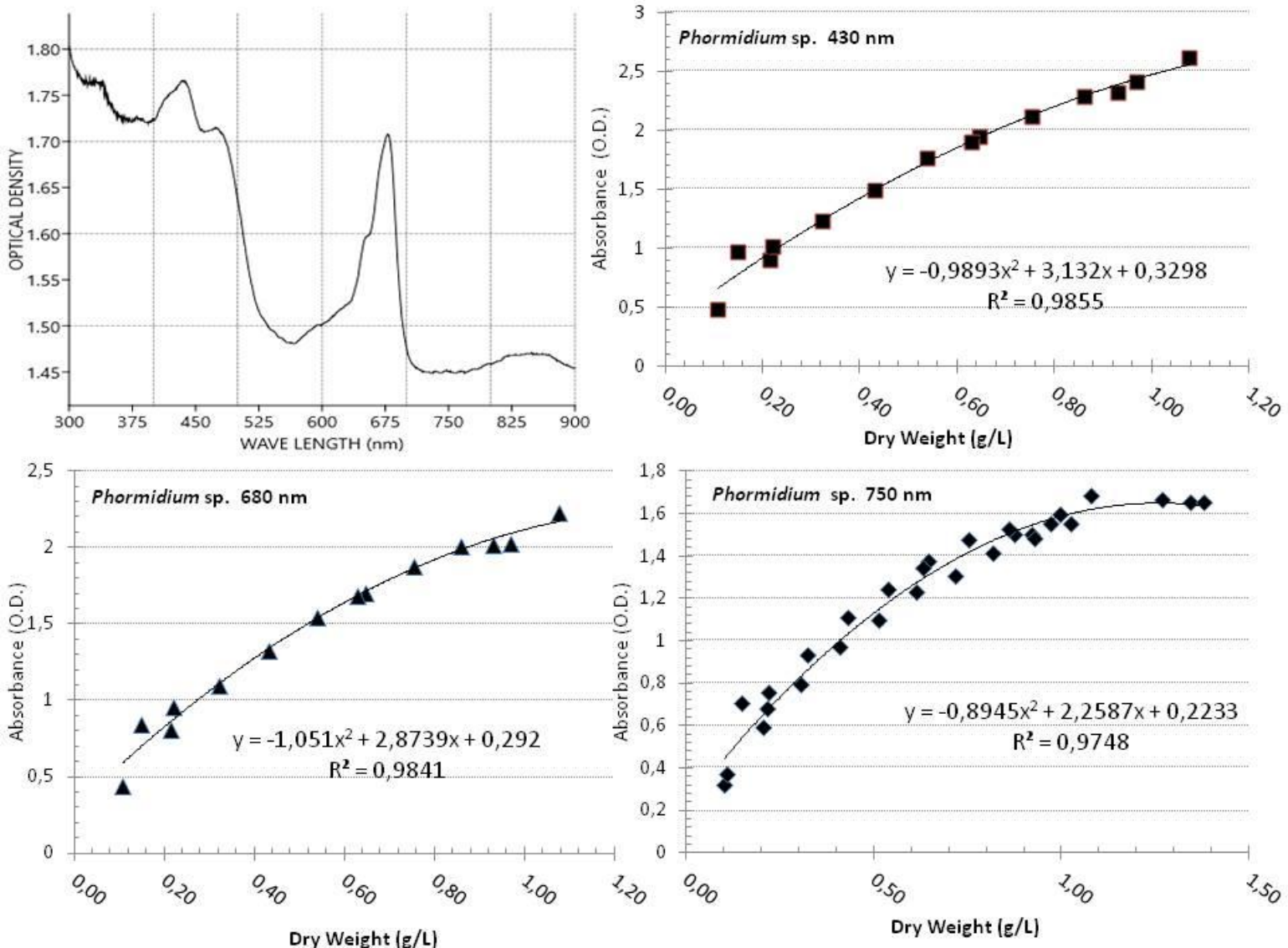

Fig. 4. The absorbance spectrum (upper left) and the relationship between absorbance and cell density for Phormidium sp. at three wavelengths (430, 680 \& $750 \mathrm{~nm})$. 
On the other side, that of selecting wavelengths that do not correspond to any absorbance peak in a spectrum, the findings of the present paper indicate towards the equally to 430 and $680 \mathrm{~nm}$ usefulness of the wavelengths of $750 \mathrm{~nm}$ (for all 3 species) and $570 \mathrm{~nm}$ for Phormidium. It seems that there is not a necessity to use exclusively wavelengths that correspond to a spectrum peak in order to get a calibration curve of O.D.-cell density. Practically any wavelength can be used as the spectrophotometer detects turbidity levels caused by the suspended cells in the vial. In the present study where for the first time we present constructed equations relating O.D. to cell density for the particular species of microalgae examined, future culturists can rely upon the equations presented here and use them to monitor their cultures provided they use exactly the wave length they choose and its relevant equation. However, in order to increase the accuracy and usefulness of the predicting equations presented here and as a final selection of the best wavelength for each species we checked the percentile deviation of each wavelength and selected those with the least standard error and deviation (Table 1). Based on the summary statistical data of the percentiles (Table 1) we indicate $680 \mathrm{~nm}$ for Nephroselmis and Amphidinium and $570 \mathrm{~nm}$ (Fig. 5) for Phormidium as the most reliable wavelengths for the estimation of their cell density.

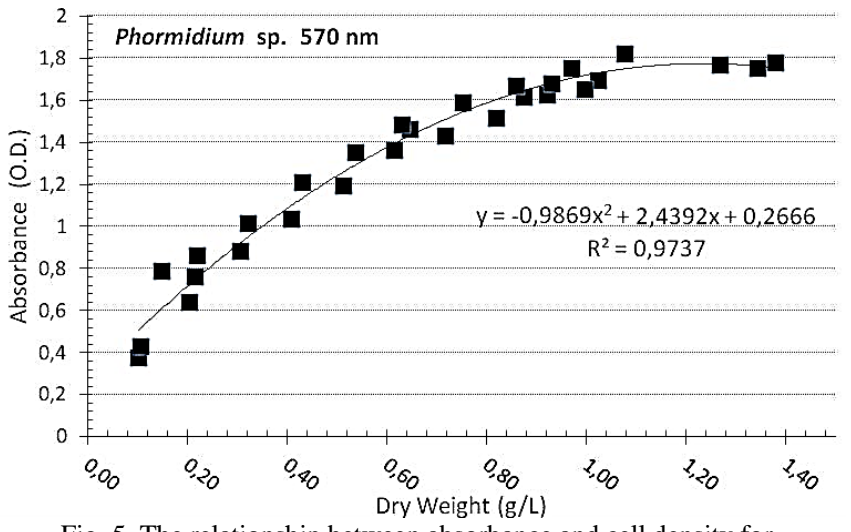

Fig. 5. The relationship between absorbance and cell density for Phormidium sp. at the wavelength of $570 \mathrm{~nm}$.

\begin{tabular}{|c|c|c|c|c|c|c|c|c|c|c|}
\hline & \multicolumn{3}{|c|}{ Nephroselmis } & \multicolumn{3}{|c|}{ Amphidinium } & \multicolumn{4}{|c|}{ Phormidium } \\
\hline & $430 \mathrm{~nm}$ & $680 \mathrm{~nm}$ & $750 \mathrm{~nm}$ & $430 \mathrm{~nm}$ & $\begin{array}{l}680 \\
\mathrm{~nm}\end{array}$ & $750 \mathrm{~nm}$ & $430 \mathrm{~nm}$ & $680 \mathrm{~nm}$ & $750 \mathrm{~nm}$ & $570 \mathrm{~nm}$ \\
\hline $\mathrm{N}$ & 28 & 10 & 20 & 16 & 16 & 10 & 14 & 14 & 29 & 29 \\
\hline Min & $-7,82$ & $-4,99$ & $-16,98$ & $-6,175$ & $-17,75$ & $-12,02$ & $-36,59$ & $-33,33$ & $-39,45$ & $-33,45$ \\
\hline $\operatorname{Max}$ & 15,049 & 15,439 & 14,674 & 15,681 & 6,639 & 11,02 & 19,779 & 17,324 & 23,232 & 22,652 \\
\hline Sum & 107,544 & 5,858 & 71,413 & 41,026 & $-60,38$ & 72,706 & $-18,46$ & $-16,26$ & $-37,55$ & $-31,56$ \\
\hline Mean & 3,84085 & 0,5858 & 3,57065 & 2,5641 & $-3,77$ & 7,2706 & $-1,318$ & $-1,161$ & $-1,29$ & $-1,088$ \\
\hline Std. error & 1,10256 & 1,7969 & 1,80172 & 1,598 & 1,504 & 2,202 & 3,1287 & 2,9123 & 1,978 & 1,8134 \\
\hline Variance & 34,0383 & 32,292 & 64,9243 & 40,90 & 36,19 & 48,50 & 137,0 & 118,7 & 113,5 & 95,37 \\
\hline $\begin{array}{c}\text { Stand. } \\
\text { deviation }\end{array}$ & 5,83423 & 5,6826 & 8,05756 & 6,395 & 6,016 & 6,964 & 11,70 & 10,89 & 10,65 & 9,765 \\
\hline 25 prentil & $-1,239$ & $-2,564$ & $-0,682$ & $-2,193$ & $-6,26$ & 6,862 & $-1,454$ & $-2,189$ & $-4,61$ & $-4,69$ \\
\hline 75 prentil & 7,51525 & 1,4962 & 9,46075 & 8,579 & $-0,19$ & 10,85 & 1,985 & 1,507 & 4,001 & 3,37 \\
\hline Skewness & $-0,3203$ & 2,2584 & $-0,9951$ & 0,765 & $-0,83$ & $-2,864$ & $-1,916$ & $-1,803$ & $-1,54$ & $-1,044$ \\
\hline Kurtosis & $-0,3382$ & 6,1508 & 0,9221 & $-0,459$ & 1,094 & 8,577 & 7,551 & 6,572 & 6,116 & 4,466 \\
\hline $\begin{array}{c}\text { Coeff. } \\
\text { variation }\end{array}$ & 151,899 & 970,05 & 225,66 & 249,4 & -159 & 95,79 & $-887,7$ & $-937,8$ & $-822,8$ & $-897,1$ \\
\hline
\end{tabular}

\section{ACKNOWLEDGMENT}

This study was financially supported by the research programm "ALGAVISION: Isolation and culture of local phytoplancton species aiming to mass production of antibacterial substances, fatty acids, pigments and antioxidants" (MIS 5048496), funded by the General Secretariat of Research and Technology of the Greek Government.

\section{REFERENCES}

[1] Shen, Y., 2014. Carbon dioxide bio-fixation and wastewater treatment via algae photochemical synthesis for biofuels production. RSC Adv. 4, 49672-49722.

[2] Cuellar-Bermudez, S.P., Garcia-Perez, J.S., Rittmann, B.E., ParraSaldívar, R., 2015. Photosynthetic bioenergy utilizing CO2: An approach on flue gases utilization for third generation biofuels. J. Clean. Prod. 98.

[3] Ravindran, B., Gupta, K.S., Won-Mo Cho, Kim, K.J., Lee, R.S., Jeong, K.-H., Lee, J.D., and Choi, H.-C., 2016. Microalgae Potential and Multiple Roles - Current Progress and Future Prospects-An Overview. 2016Sustainability 8(12):1215 DOI: 10.3390/su8121215.
[4] Padovan, A., 1992. Isolation and culture of five species of freshwater algae from the alligator rivers region, northern territory. Technical Memorandum No. 37. Australian Government Publishing Service. Canberra.

[5] Valer, R.M., Glock, L., 1998. Quantificação de algas clorofíceas de interesse ecotoxicológico a través do método espectrofotométrico. Acta Limnol. Bras. 11 (2), 149-156.

[6] Geis, S.W., Fleming, K.L., Korthals, E.T., Searle, G., Reynolds, L., Karner, D.A., 2000. Modifications to the algal growth inhibition test for use as a regulatory assay. Environ. Toxicol. Chem. 19, 36-41.

[7] Mikschofsky, H., Hammer, M., Schmidtke, J., König, P., Keil, G., Schirrmeier, H., Schmidt, K., Broer, I., 2009. Optimization of growth performance of freshly induced carrot suspensions concerning PMP production. In Vitro Cel. Develop. Biol. Plant. 45, 740-749.

[8] Ribeiro-Rodrigues, L.H., Arenzon, A., Raya-Rodriguez, M.T., Fontoura, N.F., 2011. Algal density assessed by spectrophotometry: a calibration curve for the unicellular algae Pseudokirchneriella subcapitata. J. Environ. Chem. Ecotoxicol. 3 (8), 225-228.

[9] Santos-Ballardo, U. D., Rossi, S., Hernandez, V., Vázques Gómez, R., Rendón-Unceta, C. M., Caro-Corrales, J., Valdez-Ortiz, A., 2015. A simple spectrophotometric method for biomass measurement of important microalgae species in aquaculture. Aquaculture 448, 87-92.

[10] Gallardo-Rodriguez, J., Sanchez-Miron, A., Garcia-Camacho, F., Lopez-Rosales, L., Chisti, Y., Molina-Grima, E., 2012. Bioactives from microalgal dinoflagellates. Biotechnol. Adv. 30 (6), 1673-1684.

[11] Assunção, J., Guedes, A., Malcata, F.X., 2017. Biotechnological and pharmacological applications of biotoxins and other bioactive molecules from dinoflagellates. Mar. Drugs 15 (12), 393. 
[12] López-Rosales, L., García-Camacho, F., Sánchez-Mirón, A., Beato, E.M., Chisti, Y., Grima, E.M., 2016. Pilot-scale bubble column photobioreactor culture of a marine dinoflagellate microalga illuminated with light emission diodes. Bioresour. Technol. 216, 845855 .

[13] Molina-Miras, A., Morales-Amador, A., de Vera, C., López-Rosales, L., Sánchez-Mirón, A., Souto, M., Fernández, J., Norte, M., GarcíaCamacho, F., Molina-Grima, E., 2018. A pilot-scale bioprocess to produce amphidinols from the marine microalga Amphidinium carterae: isolation of a novel analogue. Algal Res. 31, 87-98.

[14] Molina-Miras, A., López-Rosales, Sánchez-Miróna, A.L., CerónGarcía, C.M., Seoane-Parrac, S., García-Camacho, F., Molina-Grima, E., 2018. Long-term culture of the marine dinoflagellate microalga Amphidinium carterae in an indoor LED-lighted raceway photobioreactor: Production of carotenoids and fatty acids. Bioresource Technology 265, 257-267.

[15] García-Camacho, F., Sánchez-Mirón, A., Gallardo-Rodríguez, J., López-Rosales, L., Chisti, Y., Molina-Grima, E., 2014. Culture of microalgal dinoflagellates. In: Botana, L.M. (Ed.), Seafood and Freshwater Toxins: Pharmacology, Physiology, and Detection, third ed. CRC Press, Boca Raton, pp. 551-566.

[16] Fuentes-Grunewald, C., Bayliss, C., Fonlut, F., Chapuli, E., 2016. Long-term dinoflagellate culture performance in a commercial photobioreactor: Amphidinium carterae case. Bioresour. Technol. 218, 533-540.

[17] Ishikawa, C., Jomori, T., Tanaka, J., Senba, M., Mori, N., 2016. Peridinin, a carotenoid, inhibits proliferation and survival of HTLV-1infected T-cell lines. Int. J. Oncol. 49 (4), 1713-1721.

[18] Ji, M.-K.; Yun, H.-S.; Hwang, B.S.; Kabra, A.N.; Jeon, B.-H.; Choi, J. Mixotrophic cultivation of Nephroselmis sp. using industrial wastewater for enhanced microalgal biomass production. Ecol. Eng. 2016, 95, 527-533.

[19] Park, S., Ahn, Y., Pandi, K., Ji, M.K., Yun, H.-S., Choi, J.-Y., 2019. Microalgae Cultivation in Pilot Scale for Biomass Production Using Exhaust Gas from Thermal Power Plants. In: João Fernando Pereira Gomes (ed.) Optimization of Biodiesel, Methanol and Methane Production and Air Quality Improvement. MDPI Energies, 12, 3497, $14-23$.

[20] Santhose, I., Gnanadoss, J., Ramganesh, S., Elumalai, S., 2011. Enhanced Carotenoid Synthesis of Phormidium sp. in Stressed Conditions. Journal of Experimental Sciences, 2, (3), 38-44.

[21] Yalcin, D., Katircioğlu, T.H., Özer, T., Shamchi, P.M., Acikgoz Erkaya, A. İl., 2020. Evaluation of phytotherapeutic activities and phytochemical content of Phormidium autumnale Gomont from natural freshwater sources. Environ. Monit. Assess. 192: 244, 1-11. DOI. 10.1007/s10661-020-8207-4.

[22] Do Nascimento, C.T., Nass, P.P., Fernandes, S.A., Vieira, R.K., Wagner, R., Jacob-Lopes, E., Zepka, Q.L., 2020. Exploratory data of the microalgae compounds for food purposes. Data in Brief, 29, 1-9. DOI. 10.1016/j.dib.2020.105182.

[23] Havlik, I., Lindner, P., Scheper, T., Reardon, K.F., 2013. On-line monitoring of large cultivations of microalgae and cyanobacteria. Trends Biotechnol. 31 (7), 406-414.

[24] Rosas, L., Riveros, H.G., 1990. Iniciación al método científico experimental. 2nd edition. Ed. Trillas, México, D.F.

[25] Bricaud, A., Morel, A., Babin, M., Allali, K., Claustre, H., 1998 Variations of light absorption by suspended particles with chlorophyll a concentration in oceanic (case 1) eaters: analysis and implications for bio-optical models. J. Geophys. Res. 103 (13), 31033-31044.

[26] Ebenezer, V., Ki, J.S., 2013. Quantification of toxic effects of the herbicide metolachlor on marine microalgae Ditylum brightwelli (Bacillariophyceae), Prorocentrum minimum (Dinophyceae), and Tetraselmis suecica (Chlorophyceae). J. Microbiol. 51 (1), 136-139.

[27] Gómez, P. M., Romeral, G. J., Martorell, C.J., Aroca, S.A., 2016. Direct spectrophotometric method to determine cell density of Isochrysis galbana in serial batch cultures from a larger scale fedbatch culture in exponential phase. NEREIS 8, 35-43.

[28] Dziosa, K., Makowska, M., 2016. Monitoring of Chlorella sp. growth based on the optical density measurement. Maintenance Problems. 2, 197-205.

[29] American Public Health Association, 2012. Standard Methods for the Examination of Water and Wastewater 22nd edition. 